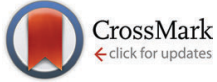

Cite this: Mol. BioSyst., 2016, 12,3435

Received 7th July 2016 Accepted 14th September 2016

DOI: $10.1039 / c 6 m b 00511 j$

www.rsc.org/molecularbiosystems

\section{A kinetic mechanism of repair of DNA containing $\alpha$-anomeric deoxyadenosine by human apurinic/apyrimidinic endonuclease 1}

\author{
N. A. Timofeyeva* and O. S. Fedorova* \\ $\alpha$-Anomers of $2^{\prime}$-deoxyadenosine $(\alpha \mathrm{dA})$ are major products of deoxyadenosine damage when DNA is \\ $\gamma$-irradiated under anoxic conditions. Such lesions are a threat to genomic stability and are known to be \\ processed by human apurinic/apyrimidinic endonuclease 1 (APE1). The aim of this study was to \\ determine whether the $\alpha$-anomeric structure enhances enzyme recognition. For this purpose, we \\ analyzed the kinetic mechanism of $\alpha \mathrm{dA}$ conversion by APE1 using a stopped-flow fluorescence \\ technique. Our data reveals that the initial formation of the complex of APE1 with an $\alpha \mathrm{dA}$-containing \\ substrate is followed by at least three conformational transitions in this complex that correspond to the \\ induced fit leading to the formation of a catalytically competent complex. A local perturbation around \\ the $\alpha \mathrm{dA}$ lesion in the DNA duplex allows APE1 to avoid the initial conformational changes observed \\ earlier in the case of the enzyme binding to an undamaged ligand, abasic-site-, tetrahydrofuran-, or \\ 5,6-dihydrouridine-containing substrates. The $\alpha \mathrm{dA}$ structure promotes recognition by the enzyme but \\ dramatically impedes formation of the catalytically competent complex and hydrolysis of the $5^{\prime}$-phosphodiester \\ bond. A step following the chemical reaction, possibly a release of the $\alpha \mathrm{dA}$-containing product, is rate-limiting \\ for the overall enzymatic process, though an $\alpha$-anomeric nucleotide at the $5^{\prime}$ terminus of the DNA nick \\ accelerates dissociation of the enzyme-product complex. Our results show that the efficiency of $\alpha \mathrm{dA}$ lesion \\ conversion by APE1 is very low. Nonetheless, $\alpha \mathrm{dA}$ repair by APE1 is probably a biologically relevant process.
}

\section{Introduction}

The human genome is continuously assaulted by various reactive species of either endogenous or exogenous origin; this process results in the formation of DNA lesions. The $\alpha$-anomer of 2 -deoxyadenosine $(\alpha \mathrm{dA})$ is one of such lesions. It arises from deoxyadenosine exposed to $\gamma$-irradiation under anaerobic conditions. ${ }^{1}$ This compound is generated by abstraction of the anomeric hydrogen atom at $\mathrm{C}^{\prime}$ by a free hydroxyl radical, which leads to epimerization at the $\mathrm{C}^{\prime}$ position. ${ }^{2,3} \alpha \mathrm{dA}$ is found to be a major product of deoxyadenosine damage when poly $(\mathrm{dA})$, poly $(\mathrm{dA}-\mathrm{dT})$, and salmon testis DNA are $\gamma$-irradiated under a nitrogen atmosphere. ${ }^{4}$ Formation of $\alpha \mathrm{dA}$ lesions in human cells may have serious consequences because the eukaryotic nucleus is a poorly oxygenated intracellular compartment. ${ }^{5,6}$ Besides, tumor cells have adapted the ability to grow in hypoxic environments, and radiation therapy provides the conditions for such damage. ${ }^{7}$

In order to sustain cellular genome integrity, DNA lesions must be repaired. The majority of damaged DNA bases are

Siberian Branch of the Russian Academy of Sciences, Institute of Chemical Biology and Fundamental Medicine, Novosibirsk 630090, Russia.

E-mail:fedorova@niboch.nsc.ru,na_timof@niboch.nsc.ru processed by the base excision repair (BER) pathway initiated by DNA glycosylases. Nevertheless, the $\alpha \mathrm{dA}$ lesion is not repaired by DNA glycosylases/apurinic/apyrimidinic (AP) lyases. Instead, Escherichia coli endonuclease IV (Nfo), Saccharomyces cerevisiae AP endonuclease 1 (Apn1), and human AP endonuclease 1 (Ape1) directly incise the phosphodiester bond $5^{\prime}$ to the lesion in DNA, as part of the nucleotide incision repair (NIR) pathway. $^{8-10}$

Because the repair pathway for the $\alpha \mathrm{dA}$ lesions is conserved from $E$. coli to yeast and humans, it has been suggested that base lesions with the $\alpha$-conformation with respect to the $N$-glycosidic bond may be biologically significant. ${ }^{10}$ The $\alpha \mathrm{dA}$ lesion constitutes a moderate block to DNA replication catalyzed by Pol I in vitro, and the nucleotide insertion frequency opposite $\alpha \mathrm{dA}$ is in the order $\mathrm{T}>\mathrm{C} \geq \mathrm{A} \gg \mathrm{G} .{ }^{11}$ Furthermore, $\alpha \mathrm{dA}$ represents a moderate block to the replication of transfected M13 vectors containing $\alpha \mathrm{dA}$, where the replicating enzyme is Pol III. The ability of in vivo replication to pass through $\alpha \mathrm{dA}$ was found to be $\sim 20 \%$ relative to the normal A base. $\alpha \mathrm{dA}$ generates a single nucleotide deletion in vivo. These data suggest that $\alpha \mathrm{dA}$ is potentially mutagenic. ${ }^{12}$

Probably, the structure of DNA containing an adA lesion should develop preexisting deformations and/or be easily 
deformable for specific recognition by AP endonucleases. Several studies have been carried out to ascertain the possible influence of a single $\alpha \mathrm{dA}$ inserted into regular oligonucleotide strands on their structures.

Initially, ${ }^{13}$ it was shown that duplexes containing a $\alpha \mathrm{dA} / \mathrm{N}$ pair ( $\mathrm{N}=\mathrm{A}, \mathrm{G}, \mathrm{C}$, or $\mathrm{T}$ ) in the middle do not undergo global conformational changes such as transitions to the $\mathrm{A}$ or $\mathrm{Z}$ forms of DNA. At the same time, the in vacuo energy minimization data suggested that precise positioning of the base and sugarphosphate backbone deviates from the canonical one. The adenine ring protrudes in the minor groove, with the N6 amino group projecting well into that groove. For the duplexes containing an $\alpha \mathrm{dA} /$ pyrimidine pair, displacement of the sugar-phosphate backbone from the canonical position is relatively minor. The $\alpha \mathrm{dA} / \mathrm{T}$ base pair was found to form two hydrogen bonds almost equivalent in distances and angles to the canonical $\mathrm{A} / \mathrm{T}$ base pair, although the second hydrogen bond forms between atoms N6 of $\alpha \mathrm{dA}$ and $\mathrm{O} 2$ of the opposing T. The movement of the N6 amino group into the minor groove is accompanied by a slight shift (inside the helix) of the opposing T. A minor displacement of the sugar-phosphate backbone occurs at the lesion site and a base immediately $5^{\prime}$ to $\alpha \mathrm{dA}$. The base-stacking interaction between $\alpha \mathrm{dA}$ and a base located $5^{\prime}$ to this lesion is interrupted. The duplexes containing an $\alpha \mathrm{dA} /$ purine pair show large distortion of the sugar-phosphate backbone. This distortion is not localized at the lesion site but extends to the surrounding sequences. The distortions in the duplex $\alpha \mathrm{dA} / \mathrm{G}$ produce a distinct kink and a bulge in the DNA backbone. ${ }^{13}$

Furthermore, ${ }^{14}$ molecular dynamics (MD) simulations of the structure and dynamics of a DNA duplex containing a single $\alpha \mathrm{dA}$ residue in an aqueous solution showed the formation of a nonclassical $\alpha \mathrm{dA} / \mathrm{T}$ pair. In one simulation, the bases tended to mimic the classical Watson-Crick pair, and two stable hydrogen bonds were observed, though the second hydrogen bond was between $\mathrm{N} 6$ of $\alpha \mathrm{dA}$ and $\mathrm{O} 2$ of the opposing $\mathrm{T}$. In another simulation, the alignment of both bases involved did not allow for any effective hydrogen bonding, only in some periods of simulation did one hydrogen bond form between N6 of $\alpha \mathrm{dA}$ and $\mathrm{O} 2$ of the opposing T. As portrayed earlier, ${ }^{13}$ it was shown that a single $\alpha \mathrm{dA} / \mathrm{T}$ base pair has a destabilizing effect mostly on its nearest neighbors, particularly with respect to sugar puckering and base stacking. ${ }^{14}$ Still, the duplex axis course was found to be less stable in the $\alpha$-anomerized model than in the reference molecule. Those authors observed competition between effective base stacking of the modified residue and its stable alignment within the pair. The effective hydrogen bonding in the $\alpha \mathrm{dA} / \mathrm{T}$ base pair forces the modified residue to adopt a conformation that weakens its stacking capability. These findings are in contrast to the classical DNA duplex structures where both types of interactions (stacking and hydrogen bonding) cooperate in stabilizing their conformations. ${ }^{14}$

The nuclear magnetic resonance (NMR) solution studies ${ }^{15}$ established that the single $\alpha \mathrm{dA}$ residue (within the $\alpha \mathrm{dA} / \mathrm{T}$ pair) flanked by cytosines $\left(5^{\prime}\right.$-C $\left.\alpha \mathrm{dAC}-3^{\prime}\right)$ is intrahelical and is stacked in a reverse Watson-Crick fashion consistent with the slight decrease in thermostability. The base stacking interactions of $\alpha \mathrm{dA}$ with its flanking nucleotides were found to be altered due to the change in chirality at $\mathrm{C}^{\prime}$. The stacked $\alpha \mathrm{dA}$ residue results in an $18^{\circ}$ kink of the helical axis into the major groove. These changes are accompanied by enlargement of the minor groove $3^{\prime}$ to the modification. The conformation of the flanking base-paired segments was not altered strongly relative to a B-type conformation. ${ }^{15}$ A comparison of different flanking sequences revealed that the minor groove topology and kink are dependent on the sequence surrounding the $\alpha \mathrm{dA}$ lesion. ${ }^{16}$

The cocrystal structures of Nfo, Apn1, or APE1 bound to a DNA duplex containing a single $\alpha \mathrm{dA}$ nucleotide have not been obtained to date. An attempt to solve the crystal structure of the E. coli Nfo-H69A mutant bound to an intact duplex DNA containing an $\alpha \mathrm{dA} / \mathrm{T}$ base pair was successful at determining the high-resolution crystal structure of Nfo-H69A bound to a NIR product. ${ }^{17}$ The $\alpha \mathrm{dA} / \mathrm{T}$ base pair was shown to be well stacked in the DNA, and the phosphate group of $\alpha \mathrm{dA}$ points toward the solvent. The $\alpha \mathrm{dA}$ base, which is rotated $180^{\circ}$ around the $\mathrm{C}^{\prime}$ '-N9 axis (compared with an adenine base) makes modified Watson-Crick contacts. Its N6 atom interacts with the $\mathrm{O} 2$ atom of the opposing $\mathrm{T}$. In contrast, the preceding base pair $(\mathrm{C} / \mathrm{G})$ is unpaired, with both bases being extrahelical. ${ }^{17}$

The kinked helical axis and the enlarged minor groove around the lesion revealed by NMR for $\alpha \mathrm{dA}$-containing $\mathrm{DNA}^{15}$ were also demonstrated in the crystal structures of an apurinic DNA substrate in complex with Endo IV ${ }^{18}$ or APE1. ${ }^{19,20}$ Thus, it was suggested that the $\alpha$-anomeric structure promotes its recognition by the enzyme because of structural distortions that are already on the path toward their values in the subsequent complex. The presence of a kink and enlarged minor groove is expected to facilitate the enzymatic access both by reducing the energetic cost of forming the initial distortion and by further reducing the energetic cost of driving the nucleic acid into its final conformation. ${ }^{15}$

The objective of the present study was to determine whether the $\alpha$-anomeric structure enhances enzyme recognition. To this end, we used the stopped-flow approach to study the conformational dynamics and the kinetic mechanism of the APE1 interaction with the $\alpha \mathrm{dA}$-containing substrates. Our data reveals that the adA structure promotes recognition by the enzyme but dramatically impedes formation of the catalytically competent complex and hydrolysis of the $5^{\prime}$-phosphodiester bond.

\section{Materials and methods}

\subsection{The enzyme and oligonucleotides}

Human APE1 was overexpressed in the BL21 (DE3) pLysS E. coli cells by means of the pXC53 plasmid carrying the APE1 gene, and was purified as described elsewhere. ${ }^{21}$ The concentration of APE1 was determined by the Bradford assay using BSA as a standard. Oligodeoxyribonucleotides (ODNs; $5^{\prime} \rightarrow 3^{\prime}$ ) d(ATGCACATCGTCTACATGCTTATGCAGTCA), d(ATGCACATCG TCTAACTGCTTATGCAGTCA), d(TGACTGCATA( $\alpha A)$ GCAXGTAG ACGATGTGCAT) $\left(\mathrm{X}=\mathrm{T}\right.$ or ${ }^{\mathrm{NH} 2 \mathrm{C} 6} \mathrm{~T}$, which is 5 -[ $N$-(trifluoroacetylaminohexyl)-3-acrylimido]-2'-deoxyuridine [Amino-Modifier C6 dT; 
Glen Research, USA], a modified thymine containing a hexamethylene amino linker on the C5 atom), d(TGACTGCATA $(\alpha \mathrm{A})$ GCAG $\left({ }^{\mathrm{NH} 2 \mathrm{C} 6}\right.$ T)TAGACGATGTGCAT) and d(TGACTGCATA) were synthesized in the Laboratory of Bionanotechnology (Institute of Chemical Biology and Fundamental Medicine, the Siberian Branch of the Russian Academy of Sciences, Russia) by the standard phosphoramidite method using monomers from Glen Research (USA) and were purified using anion exchange and reversed-phase high-performance liquid chromatography (HPLC). Oligodeoxyribonucleotides d(TGACTGCAT $(2-\mathrm{aPu})(\alpha \mathrm{A})$ GCATGTAGACGATGTGCAT) (where 2-aPu is 2-aminopurine: a highly fluorescent analog of adenine) and $\operatorname{pd}((\alpha \mathrm{A}) \mathrm{GCATGTA}$ GACGATGTGCAT) were synthesized by Eurogentec (France) and kindly provided to us by Dr Alexander A. Ishchenko (CNRS UMR8200 Université Paris-Sud XI, Institut de Cancérologie Gustave Roussy, Villejuif, France). The concentration of each individual single-stranded (ss) ODN was determined via absorbance at $260 \mathrm{~nm}$ with the extinction coefficients calculated from the nearest-neighbor data for mono- and dinucleotides. ${ }^{22}$

\subsection{Oligonucleotide labeling}

A fluorophore, 5-(and 6-)carboxytetramethylrhodamine (TAMRA), was covalently attached to ODNs d(TGACTGCATA $(\alpha A) G C A$ $\left({ }^{\mathrm{NH} 2 \mathrm{C} 6} \mathrm{~T}\right)$ GTAGACGATGTGCAT) and d(TGACTGCATA $(\alpha \mathrm{A})$ GCAG $\left({ }^{\mathrm{NH} 2 \mathrm{C} 6} \mathrm{~T}\right)$ TAGACGATGTGCAT) at position 5 of the modified thymine heterocyclic base $\left({ }^{\mathrm{NH} 2 \mathrm{C} 6} \mathrm{~T}\right)$ through a $\mathrm{C} 6$ amino linker. The ODN (10 optical units in $20 \mu \mathrm{L}$ of $\mathrm{H}_{2} \mathrm{O}$ ) was mixed with $150 \mu \mathrm{L}$ of $0.1 \mathrm{M} \mathrm{Na}_{2} \mathrm{~B}_{4} \mathrm{O}_{7}$ (pH 8.5). 5(6)-TAMRA succinimidyl ester [5(6)-TAMRA-SE; $4 \mathrm{mg}$ ] was dissolved in $64 \mu \mathrm{L}$ of dimethyl formamide (DMF). The ODN solution was treated with $32 \mu \mathrm{L}$ of 5(6)-TAMRA-SE in DMF. The reaction mixture was incubated with constant shaking for $1 \mathrm{~h}$ at room temperature. Then, $16 \mu \mathrm{L}$ of 5(6)-TAMRA-SE in DMF was added, and the reaction mixture was incubated for one more hour. The incubation was continued for another $2 \mathrm{~h}$ after addition of the remaining $16 \mu \mathrm{L}$ of 5(6)-TAMRA-SE in DMF. After that, the reaction mixture was incubated without shaking for $3 \mathrm{~h}$ at $4{ }^{\circ} \mathrm{C}$, and precipitated with $2 \% \mathrm{LiClO}_{4}$ in acetone. Purification of the reaction mixture to get rid of the free dye was performed using gel filtration chromatography. The TAMRA-labeled OND was separated from the unlabeled ODN using denaturing polyacrylamide gel electrophoresis (PAGE) in a $20 \%$ acrylamide gel containing $8 \mathrm{M}$ urea. When necessary, the $5^{\prime}$ terminus of the ODN d(TGACTGCATA $(\alpha A)$ GCATGTAGACGATGTGCAT) was labeled with ${ }^{32} \mathrm{P}$ according to the standard procedure ${ }^{23}$ using T4 polynucleotide kinase $(20 \mathrm{U}$; SibEnzyme, Russia) and $\left[\gamma^{32} \mathrm{P}\right]$ ATP (Biosan, Russia). The oligonucleotide duplexes used in this study are presented in Fig. 1.

\subsection{Kinetic fluorescence experiments}

The kinetics of the APE1 interactions with the DNA substrates was recorded on an SX.20 stopped-flow spectrometer (Applied Photophysics, Ltd, UK). Fluorescence signals of either the protein tryptophan residues, the substrate TAMRA or the 2-aPu residues were detected. The dead time of the instrument was $1.04 \mathrm{~ms}$. APE1 and $\alpha \mathrm{dA}$-containing DNA were rapidly mixed at $25{ }^{\circ} \mathrm{C}$ in a reaction buffer consisting of $20 \mathrm{mM}$ HEPES/KOH pH 6.8,

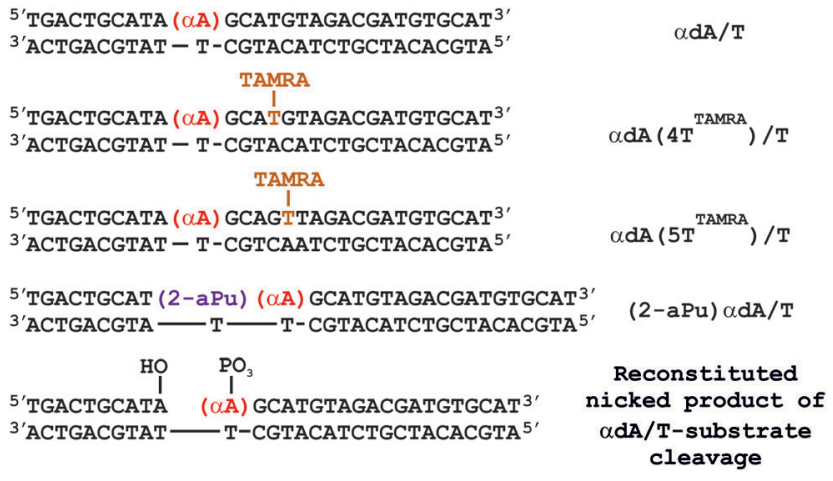

Fig. 1 Schematic presentation of various DNA duplexes used in this study.

$50 \mathrm{mM} \mathrm{KCl}$, and $0.01 \mathrm{mM} \mathrm{MgCl}$. The Trp fluorescence intensity of APE1 was recorded at $1 \mu \mathrm{M}$ concentration of protein in the reaction chamber, and the 0.5-2.0 $\mu \mathrm{M}$ concentration of a double-stranded (ds) ODN substrate. The TAMRA fluorescence intensity and fluorescence anisotropy were measured at $1 \mu \mathrm{M}$ substrate concentration in the reaction chamber, at an APE1 concentration of 1.0-3.0 $\mu \mathrm{M}$. The 2-aPu fluorescence was measured at 1 or $3 \mu \mathrm{M}$ substrate concentration in the reaction chamber, at 1.0-1.5 $\mu \mathrm{M}$ or 3.0-4.5 $\mu \mathrm{M}$ APE1, respectively. The emitted fluorescence of Trp in APE1 was detected through a long-pass Schott filter WG320 at $\lambda_{\mathrm{em}}>320 \mathrm{~nm}$ with excitation at $281 \mathrm{~nm}$. The emitted fluorescence of TAMRA was detected through a long-pass filter at $\lambda_{\mathrm{em}}>580 \mathrm{~nm}$ with excitation at $550 \mathrm{~nm}$ (Lytkarino Optical Glass Factory, Russia). The emitted fluorescence of 2-aPu was detected through a long-pass Corion filter LG-370 at $\lambda_{\mathrm{em}}>370 \mathrm{~nm}$ with excitation at $310 \mathrm{~nm}$. The fluorescence was excited using the monochromator of the stopped-flow instrument. For anisotropy measurements, the light was polarized by means of calcite prisms for the incident beam and in front of each of the two photomultiplier detectors arranged in a T-configuration. The stopped-flow spectrometer was equipped with an open cuvette. Diffusion from the open cuvette could be a source of additional error in the kinetic parameters of very slow processes. To prevent such an error, 2-aPu fluorescence traces of the substrate upon its interaction with APE1 were also recorded using the Cary Eclipse spectrofluorometer (Agilent Technologies, USA) equipped with a closed cuvette. In the latter case, solutions of the enzyme and substrate were incubated separately at $25{ }^{\circ} \mathrm{C}$ for $10 \mathrm{~min}$ before manual mixing within the cuvette. The reaction was allowed to proceed at $25{ }^{\circ} \mathrm{C}$ in the reaction buffer mentioned above. The emitted fluorescence of $2-\mathrm{aPu}$ was measured at $370 \mathrm{~nm}\left(\lambda_{\mathrm{ex}}=310 \mathrm{~nm}\right)$. The excitation and emission wavelengths were adjusted using the monochromators of the Cary Eclipse instrument. At the start of the process, each fluorescence trace of $\operatorname{Trp}(t \leq 10 \mathrm{~s})$ or $2-\mathrm{aPu}(t \leq 200 \mathrm{~s})$ represented the average of $\geq 4$ experiments, and each TAMRA fluorescence anisotropy or fluorescence intensity trace $(t<1 \mathrm{~s})$ represented the average of $\geq 12$ experiments. For longer periods, no averaging was performed. The resulting kinetic traces were numerically integrated and fitted using nonlinear regression analysis in the DynaFit software (BioKin, USA). ${ }^{24}$ The initial regions of the 


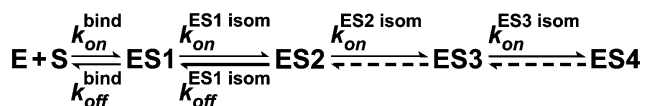

Fig. 2 The minimal kinetic scheme derived from kinetic traces (both fluorescence and anisotropy of fluorescence).

kinetic traces were fitted to a kinetic scheme containing one bimolecular step of formation of the enzyme-substrate complex. Furthermore, consecutive spreading of the time slot with simultaneous elaboration of the kinetic mechanism was performed. The subsequent steps were first order (or pseudofirst order) and corresponded to isomerization of the enzymesubstrate complex, as they were observed prior to the catalytic step of hydrolysis of the substrate $5^{\prime}$-phosphodiester bond. Thus, a minimal kinetic scheme describing the empirical data was determined (Fig. 2).

The kinetic parameters were obtained by numerical integration of the system of kinetic differential equations (eqn (1)) and the least-square global nonlinear fitting of the total fluorescence intensity (or fluorescence anisotropy) ( $F$, total fluorescence intensity or fluorescence anisotropy; $F_{\mathrm{b}}$, background fluorescence intensity or fluorescence anisotropy; $f_{i}$, the coefficient of specific fluorescence [or specific anisotropy] for each discernible DNA conformer; $\left[S_{i}(t)\right]$, concentration of the conformer at any given time point $t[i=0$ denotes free DNA; $i>0$ means enzyme-DNA complexes]). ${ }^{25,26}$

$$
\begin{aligned}
& \frac{\mathrm{d}[\mathrm{S}]}{\mathrm{d} t}=-k_{\mathrm{on}}^{\mathrm{bind}}[\mathrm{E}][\mathrm{S}]+k_{\mathrm{off}}^{\mathrm{bind}}[\mathrm{ES} 1] \\
& \frac{\mathrm{d}[\mathrm{E}]}{\mathrm{d} t}=-k_{\mathrm{on}}^{\mathrm{bind}}[\mathrm{E}][\mathrm{S}]+k_{\mathrm{off}}^{\mathrm{bind}}[\mathrm{ES} 1] \\
& \frac{\mathrm{d}[\mathrm{ES} 1]}{\mathrm{d} t}=k_{\mathrm{on}}^{\mathrm{bind}}[\mathrm{E}][\mathrm{S}]-\left(k_{\mathrm{off}}^{\mathrm{bind}}+k_{\mathrm{on}}^{\mathrm{ES} 1 \text { isom }}\right)[\mathrm{ES} 1]+k_{\mathrm{off}}^{\mathrm{ES} 1 \text { isom }}[\mathrm{ES} 2] \\
& \frac{\mathrm{d}[\mathrm{ES} 2]}{\mathrm{d} t}=k_{\mathrm{on}}^{\mathrm{ES} 1 \text { isom }}[\mathrm{ES} 1]-\left(k_{\mathrm{off}}^{\mathrm{ES} 1 \text { isom }}+k_{\mathrm{on}}^{\mathrm{ES} 2 \text { isom }^{*}}\right)[\mathrm{ES} 2] \\
& \frac{\mathrm{d}[\mathrm{ES} 3]}{\mathrm{d} t}=k_{\mathrm{on}}^{\mathrm{ES} 2 \text { isom }^{*}}[\mathrm{ES} 2]-k_{\mathrm{on}}^{\mathrm{ES} 3 \text { isom }^{*}}[\mathrm{ES} 3]
\end{aligned}
$$

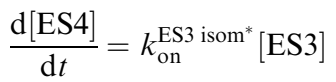

$$
\begin{aligned}
& F=F_{\mathrm{b}}+\sum_{i=0}^{n} f_{i}\left[S_{i}(t)\right]
\end{aligned}
$$

The kinetic parameters were determined by global fitting of a series of fluorescence (or anisotropy of fluorescence) traces obtained at different concentrations of the reactants. During the fitting procedure, all relevant rate constants for the forward and reverse reactions as well as the specific molar response factors for all intermediate complexes were optimized.

\subsection{Steady-state fluorescence titration}

To analyze the binding affinity of APE1 for an $\alpha$ dA-containing DNA substrate and for the product of this substrate cleavage, the enzyme was titrated in the reaction buffer (see above) under steady-state conditions with the adA-substrate or with the ODNs reconstituting the products of substrate cleavage. The emitted fluorescence of Trp in the protein was measured at $330 \mathrm{~nm}\left(\lambda_{\mathrm{ex}}=281 \mathrm{~nm}\right)$ using a Cary Eclipse spectrofluorometer (Agilent Technologies). The excitation and emission wavelengths were adjusted using the monochromators supplied with the instrument. Each point of the fluorescence titration curve was obtained by measurement of the fluorescence intensity of the separate solutions $(80 \mu \mathrm{L})$ containing the enzyme $(1 \mu \mathrm{M})$ and dsODN $(0.5-20 \mu \mathrm{M})$. Each mixture of APE1 with the reaction product was incubated at $25{ }^{\circ} \mathrm{C}$ for $10 \mathrm{~min}$ before analysis. In the case of APE1 titration with an adA-containing substrate, solutions of enzyme and substrate were incubated separately at $25{ }^{\circ} \mathrm{C}$ for $10 \mathrm{~min}$ before manual mixing in the cuvette. The time from the mixing to the fluorescence measuring was no more than $1 \mathrm{~min}$. Within this period, no more than $1 \%$ of an $\alpha \mathrm{dA}$-containing substrate was cleaved, thus most of the substrate was unchanged. The fluorescence intensity values $(F)$ in the presence of oligonucleotides were adjusted for the inner filter effect due to oligonucleotides' absorption at $281 \mathrm{~nm}$ as described elsewhere. ${ }^{27}$ The dissociation constants of the enzyme-substrate (or enzymeproduct) complexes were calculated from the dependence of the enzyme's fluorescence intensity on the dsODN concentration according to the following equations:

$$
K_{\mathrm{d}}=\frac{[\mathrm{L}][\mathrm{E}]}{[\mathrm{EL}]}
$$

The intensity of detected fluorescence $F$ can be expressed as

$$
\begin{gathered}
F=f_{\mathrm{E}} \times[\mathrm{E}]+f_{\mathrm{EL}} \times[\mathrm{EL}] \\
f_{\mathrm{E}}=F_{0} /[\mathrm{E}]_{0} ; f_{\mathrm{EL}}=F_{\mathrm{lim}} /[\mathrm{E}]_{0}
\end{gathered}
$$

A combination of eqn (2) and (3), and the mass balance equations yields the relation of observed fluorescence intensity $F$ to $K_{\mathrm{d}}$ :

$$
\begin{aligned}
F= & f_{\mathrm{EL}}[\mathrm{E}]_{0}+\left(f_{\mathrm{E}}-f_{\mathrm{EL}}\right) \\
& \times\left\{\frac{[\mathrm{E}]_{0}-[\mathrm{L}]_{0}-K_{\mathrm{d}}}{2}+\sqrt{\left(\frac{[\mathrm{E}]_{0}-[\mathrm{L}]_{0}-K_{\mathrm{d}}}{2}\right)^{2}+K_{\mathrm{d}}[\mathrm{E}]_{0}}\right\}
\end{aligned}
$$

where $F_{0}, F_{\text {lim }}$ are the fluorescence intensities at $[\mathrm{L}]=0$ and at saturating concentrations of the ligand, respectively; $f_{\mathrm{E}}$ and $f_{\mathrm{EL}}$ are specific fluorescence intensities of the free enzyme and of the complex, respectively; $[\mathrm{L}]_{0}$ and $[\mathrm{E}]_{0}$ are the total concentrations of the ODN ligand and protein, respectively; and [L], [E], and $[\mathrm{EL}]$ are the concentrations of the free ligand, enzyme, and their complex, respectively. ${ }^{25}$

\subsection{Incision assays of a $\left[{ }^{32} \mathrm{P}\right]$-labeled $\alpha \mathrm{dA}$-substrate}

Two series of time course experiments with cleavage of a $5^{\prime}-\left[{ }^{32} \mathrm{P}\right]$-labeled $\alpha \mathrm{dA}$-containing substrate were conducted at $25{ }^{\circ} \mathrm{C}$ in the reaction buffer (see above). In one series, the reaction solution contained $1 \mu \mathrm{M}$ APE1 and $0.75,1.0$, or $1.25 \mu \mathrm{M}$ adA-DNA, and in the other series, the reaction solution contained $20 \mu \mathrm{M}$ APE1 and $0.5,0.75$, or $1.0 \mu \mathrm{M} \alpha \mathrm{dA}$-DNA. The enzyme was 
rapidly added to the ${ }^{32} \mathrm{P}$-labeled substrate. The reaction was quenched at designated intervals by addition of reaction mixture aliquots into thin-walled tubes that contained hot doubledistilled water (these tubes were placed in boiling water beforehand). The tubes containing the reaction mixture aliquots were incubated for $2 \mathrm{~min}$ in boiling water and were then cooled to room temperature. To digest the insoluble enzyme-DNA complex that partially formed after the heating, the reaction mixture aliquots were treated with trypsin (APE1 : trypsin = 12:1) in $50 \mathrm{mM} \mathrm{NH} \mathrm{NHCO}_{3}$ at $37{ }^{\circ} \mathrm{C}$ for $16-18 \mathrm{~h}$. The loading dye solution containing $8 \mathrm{M}$ urea was added to the reaction mixture aliquots, which were then heated at $90{ }^{\circ} \mathrm{C}$ for $3 \mathrm{~min}$. The substrates were separated from the products via denaturing PAGE in $20 \%$ acrylamide gels containing $7 \mathrm{M}$ urea at $50{ }^{\circ} \mathrm{C}$. The gels were dried, and the bands were visualized using a Molecular Imager FX phosphorimager (Bio-Rad, USA) and quantified in the Gel-Pro Analyzer software (Media Cybernetics, USA). Each kinetic curve was fitted separately to a one-exponential equation using the OriginPro software (OriginLab Corporation, USA). For the kinetic curves series obtained at $20 \mu \mathrm{M}$ APE1, the weighted average of the observed kinetic constant $(\bar{k})$ was calculated as follows:

$$
\bar{k}=\frac{\sum_{i=1}^{n} \frac{1}{\sigma_{i}^{2}} \cdot k_{i}}{\sum_{i=1}^{n} \frac{1}{\sigma_{l}^{2}}}
$$

where $k_{i}$ is the value of the observed kinetic constant obtained by fitting each kinetic curve, $\sigma_{i}$ is the standard deviation of this value, and $n$ is the number of curves in the kinetic series. The standard deviation of the weighted average $\bar{k}(s(\bar{k}))$ was calculated as follows:

$$
s(\bar{k})=\left[\sum_{i=1}^{n} \frac{1}{\sigma_{l}^{2}}\right]^{-\frac{1}{2}}
$$

\section{Results}

\subsection{Equilibrium binding of APE1 to adA-DNA}

To determine the binding affinity of APE1 for a DNA substrate containing an $\alpha \mathrm{dA} / \mathrm{T}$ pair and for the product of cleavage of this substrate, the enzyme was titrated under steady-state conditions with the corresponding DNA. The equilibrium constant for dissociation of the APE1 complex with the $\alpha \mathrm{dA}$-containing substrate $(\alpha \mathrm{dA} / \mathrm{T}), K_{\mathrm{d}}^{\mathrm{S}}$, was determined by recording the dependence of the enzyme fluorescence intensity on the substrate concentration (Fig. 3). The fitted value of $K_{\mathrm{d}}^{\mathrm{S}}$ is equal to $3.3 \pm 0.2 \mu \mathrm{M}$. Most of the substrate $(\sim 99 \%)$ was unchanged under the conditions used in this experiment (see section Steady-state fluorescence titration in the Materials and methods section and Fig. 4), and therefore, this $K_{\mathrm{d}}^{\mathrm{S}}$ value does reflect the interaction of APE1 with the substrate but not with the product. The equilibrium constant for dissociation of the complex of APE1 with the $\alpha \mathrm{dA}$-product $\left(K_{\mathrm{d}}^{\mathrm{P}}\right)$ was determined by recording the dependence of the enzyme fluorescence intensity on the concentration of

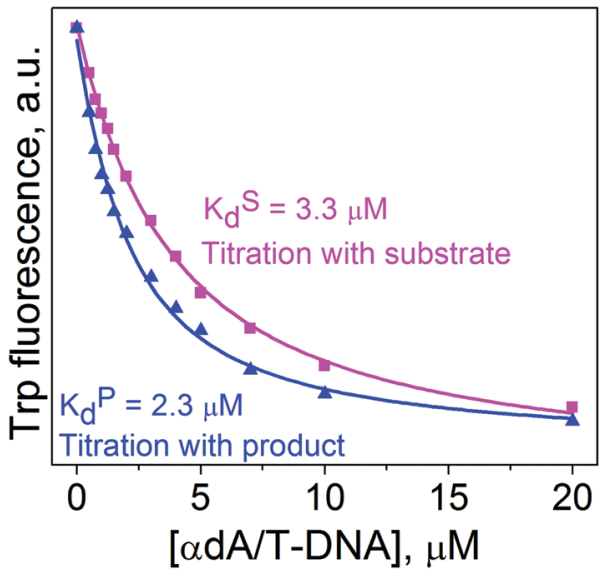

Fig. 3 Equilibrium binding of APE1 to $\alpha \mathrm{dA}$-DNA. Fluorescence titration of $1 \mu \mathrm{M}$ APE1 with the $\alpha \mathrm{dA} / \mathrm{T}$-containing substrate (magenta squares) or with the ODNs reconstituting the products of substrate cleavage (blue triangles). a.u., arbitrary units.

the product of $\alpha \mathrm{dA}$-substrate cleavage (Fig. 3). To reconstitute the reaction product, we used a nicked oligonucleotide duplex containing the $\alpha \mathrm{dA}$ residue at the $5^{\prime}$ terminus at the site of the nick (Fig. 1). The fitted value of $K_{\mathrm{d}}^{\mathrm{P}}$ is equal to $2.3 \pm 0.2 \mu \mathrm{M}$, which is 1.5 -fold lower than $K_{\mathrm{d}}^{\mathrm{S}}$. The comparison of the obtained $K_{\mathrm{d}}^{\mathrm{S}}$ and $K_{\mathrm{d}}^{\mathrm{P}}$ values showed that APE1 binds the $\alpha \mathrm{dA}$-containing product 1.5-fold more strongly than the $\alpha \mathrm{dA}$-containing substrate. According to these data, we believe that the product of adA-containing substrate cleavage may inhibit APE1 competitively in the process of hydrolysis of the $\alpha \mathrm{dA}$-containing substrate.

\subsection{Incision assays of the $\left[{ }^{32} \mathrm{P}\right]$-labeled $\alpha \mathrm{dA}$-containing substrate}

To determine the rate of accumulation of the incised product, PAGE was used to follow the time courses for product formation during processing of the $5^{\prime}-\left[{ }^{32} \mathrm{P}\right]$-labeled $\alpha \mathrm{dA} / \mathrm{T}$-containing substrate by APE1. Two series of time course experiments on product accumulation were performed. One series was conducted at the APE1 concentration of $1.0 \mu \mathrm{M}$ and at $0.75,1.0$, or $1.25 \mu \mathrm{M}$ $\alpha \mathrm{dA} / \mathrm{T}$-containing substrate (Fig. $4 \mathrm{~A}$ ). Under these conditions, only $\sim 20 \%$ of the substrate was in complex with the enzyme as the $K_{\mathrm{d}}^{\mathrm{S}}$ was equal to $3.3 \mu \mathrm{M}$. To process the substrate completely, APE1 should undergo multiple turnovers. Therefore, in our study, such concentrations were termed multiple-turnover conditions. The resulting time traces showed that the rate of product accumulation depends inversely on the initial concentration of the substrate. To determine the maximal rate of incision $5^{\prime}$ to the $\alpha \mathrm{dA}$ lesion, a second series of experiments were conducted under the conditions where APE1 $(20 \mu \mathrm{M})$ was present in excess over the substrate $(0.5,0.75$, or $1 \mu \mathrm{M})$ (Fig. $4 \mathrm{~B})$. Under these conditions, $\sim 90 \%$ of the substrate was in complex with the enzyme. To process $\sim 90 \%$ of the substrate, APE1 had to undergo a single turnover; therefore, such concentrations were termed singleturnover conditions.

APE1 was found to cleave $\sim 90 \%$ of the $\alpha \mathrm{dA}$-containing substrate within $7 \mathrm{~h}$ under single-turnover conditions (Fig. 4B). 

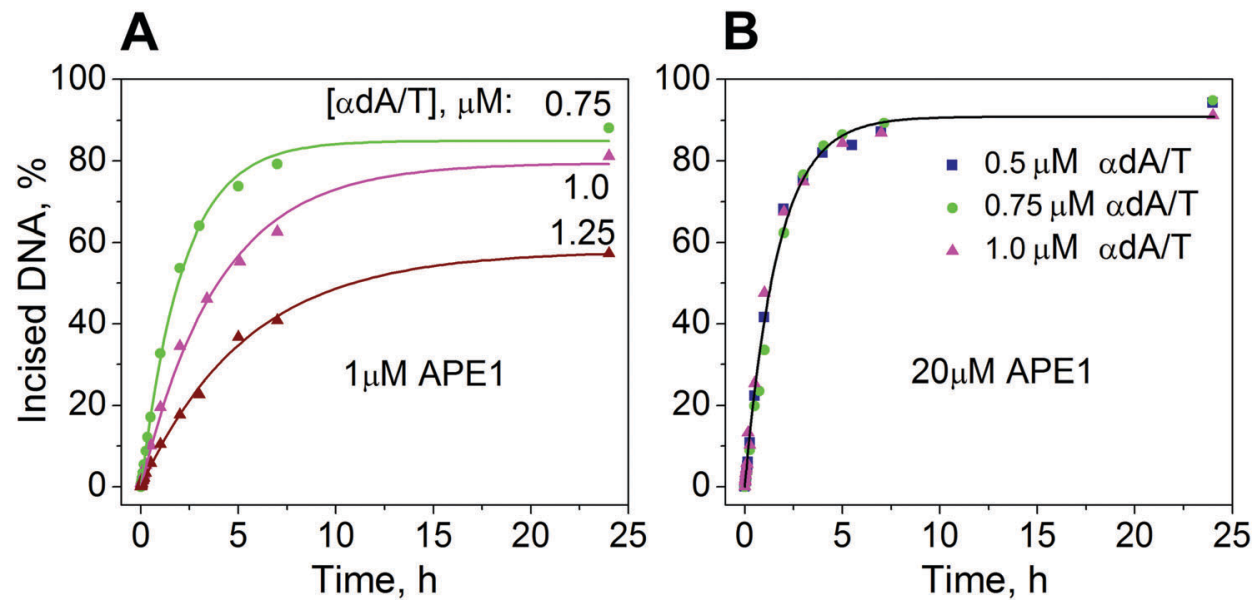

Fig. 4 Incision assays of the $\left[{ }^{32} \mathrm{P}\right]$-labeled $\alpha \mathrm{dA}$-containing substrate. Time courses of cleavage of a $\left.5^{\prime}-{ }^{32} \mathrm{P}\right]-\alpha \mathrm{dA} / \mathrm{T}$-containing substrate by APE1 $[1 \mu \mathrm{M}(\mathrm{A})$ or $20 \mu \mathrm{M}(\mathrm{B})]$. Concentrations of the substrate are indicated.

Under multiple-turnover conditions, this protein cleaved $40-80 \%$ of the $\alpha \mathrm{dA}$-containing substrate, depending on the substrate concentration, within the same period (Fig. 4A).

Previously, ${ }^{28}$ APE1 was shown to cleave more than $60 \%$ of a DHU-containing substrate within $35 \mathrm{~h}$ under multiple-turnover conditions. The time course of accumulation of the incised DHU-product showed a rapid burst of the product for periods of $<20 \mathrm{~s}$ followed by a slow increase in the amount of the product. The burst amplitude was less than the initial concentration of the enzyme, although $100 \%$ of the APE1 molecules were shown to be capable of binding. We hypothesized that the decreased amplitude of the initial product accumulation means that the enzyme exists in two conformations that are in equilibrium. At the start, one part of the enzyme exists in the conformation that is energetically less favorable but more active for DHU-substrate cleavage. Another part of the enzyme exists in the conformation that is energetically more favorable but significantly less active for cleavage of this substrate.

In the present work, we did not observe a burst in the kinetic curves of accumulation of the $\alpha \mathrm{dA}$-containing product (Fig. 4). Each kinetic curve was fitted separately to a one-exponential equation.

Under single-turnover conditions (Fig. 4B), the rate of product accumulation did not depend on the initial concentration of the $\alpha \mathrm{dA}$-containing substrate. Probably, this rate was limited either by the rate of the enzymatic hydrolysis of the $5^{\prime}$-phosphodiester bond of the substrate or by the rate of conformational rearrangement (in the enzyme-substrate complex) that occurred prior to the incision reaction and led to the formation of the catalytically competent complex. The weighted average of the observed kinetic constant of product accumulation was $(1.57 \pm 0.04) \times 10^{-4} \mathrm{~s}^{-1}$ for the series of kinetic curves obtained under single-turnover conditions (Table 1 ). The value of this constant was $\sim 5$ orders of magnitude lower than the values of the rate constants for enzymatic hydrolysis of the $5^{\prime}$-phosphodiester bond in DHU- or AP site-containing substrates. ${ }^{25,28}$

Meanwhile, under multiple-turnover conditions, the rate of product accumulation was limited by a slow step that follows the chemical reaction. This step possibly corresponded to the enzyme release from the stable complex with a nicked adA-containing product. An interesting outcome of this experiment was that the rate of product accumulation under multiple-turnover conditions decreased with increasing concentrations of the adA-containing substrate (Fig. 4A). These data also indicated that the $\alpha \mathrm{dA}$-containing product inhibits APE1 competitively in the process of hydrolysis of the $\alpha \mathrm{dA}$-containing substrate. The values of the observed equilibrium kinetic constants of product accumulation were $(1.29 \pm 0.05) \times 10^{-4} \mathrm{~s}^{-1},(0.70 \pm 0.03) \times$ $10^{-4} \mathrm{~s}^{-1}$ and $(0.51 \pm 0.02) \times 10^{-4} \mathrm{~s}^{-1}$ for reactions with $0.75,1.0$, or $1.25 \mu \mathrm{M} \alpha \mathrm{dA}$-containing substrate, respectively (Table 1). These values were lower than the value of the kinetic constant of product accumulation under single-turnover conditions $(1.57 \pm 0.04) \times$ $10^{-4} \mathrm{~s}^{-1}$. Thus, the APE1 release from the complex with the adA-containing product seems to be limiting the overall enzymatic process of hydrolysis of the $\alpha \mathrm{dA}$-containing substrate and appears to determine its rate under the steady-state conditions.

\subsection{Invariance of $\operatorname{Trp}$ fluorescence intensity during the interaction of APE1 with an adA-containing substrate}

To determine the kinetic mechanism of APE1 interaction with an $\alpha \mathrm{dA}$-containing substrate, an effort was made to record the conformational changes in the enzyme using a stopped-flow approach with detection of intrinsic tryptophan (Trp) fluorescence. We expected that the binding of the adA-containing substrate would result in changes in intrinsic APE1 fluorescence because of conformational rearrangements in the enzyme. Unexpectedly, no significant changes in protein fluorescence intensity were observed during the interaction of APE1 with the adA-containing substrate (data not shown). In contrast, earlier we observed ${ }^{25}$ considerable changes in Trp fluorescence intensity during APE1 interaction with substrates containing an AP site, (3-hydroxytetrahydrofuran2-yl)methyl phosphate (F, tetrahydrofuran), or DHU. These changes reflected the formation of enzyme-substrate complexes and subsequent conformational rearrangements of these complexes. Moreover, the kinetics of APE1 binding to an undamaged DNA ligand (L) showed two phases of changing Trp fluorescence. ${ }^{25}$ 
Table 1 Rate constants for APE1 interactions with adA-containing DNA, corresponding to the kinetic scheme presented in Fig. 9

\begin{tabular}{|c|c|c|c|c|c|c|c|}
\hline & $\begin{array}{l}k_{\mathrm{on}}^{\mathrm{bind}} \\
\left(\mathrm{M}^{-1} \mathrm{~s}^{-1}\right) \times 10^{-8}\end{array}$ & $\begin{array}{l}k_{\text {off }}^{\text {bind }} \\
\left(\mathrm{s}^{-1}\right)\end{array}$ & $\begin{array}{l}k_{\mathrm{on}}^{\mathrm{ES} 1 \text { isom }} \\
\left(\mathrm{s}^{-1}\right)\end{array}$ & $\begin{array}{l}k_{\text {off }}^{\mathrm{ES} 1 \text { isom }} \\
\left(\mathrm{s}^{-1}\right)\end{array}$ & $\begin{array}{l}k_{\mathrm{on}}^{\mathrm{ES} 2 \text { isom }} \\
\left(\mathrm{s}^{-1}\right) \times 10^{3}\end{array}$ & $\begin{array}{l}k_{\mathrm{on}}^{\mathrm{ES} 3} \text { isom } \\
\left(\mathrm{s}^{-1}\right) \times 10^{4}\end{array}$ & $\begin{array}{l}k^{\mathrm{cut}} \\
\left(\mathrm{s}^{-1}\right) \times 10^{4}\end{array}$ \\
\hline $\begin{array}{l}\alpha \mathrm{dA}\left(4 \mathrm{~T}^{\mathrm{TAMRA}}\right) / \mathrm{T} \\
\text { Fluorescence anisotropy recording } \\
\text { Fluorescence recording }\end{array}$ & $1.5 \pm 0.2$ & $\leq 1$ & $17.2 \pm 0.8$ & $15.8 \pm 0.4$ & & & \\
\hline $\begin{array}{l}\alpha \mathrm{dA}\left(5 \mathrm{~T}^{\mathrm{TAMRA}}\right) / \mathrm{T} \\
\text { Fluorescence anisotropy recording } \\
\text { Fluorescence recording }\end{array}$ & $1.6 \pm 0.2$ & $\leq 1$ & $15.2 \pm 0.6$ & $17.8 \pm 0.4$ & $7.8 \pm 0.1$ & & \\
\hline $\begin{array}{l}(2-\mathrm{aPu}) \alpha \mathrm{dA} / \mathrm{T} \\
{[\alpha \mathrm{dA} / \mathrm{T}]=3 \mu \mathrm{M}} \\
\{[\alpha \mathrm{dA} / \mathrm{T}]=1 \mu \mathrm{M}\} \\
\text { Fluorescence recording }\end{array}$ & $1.4 \pm 0.2$ & $\leq 1$ & & & $\begin{array}{l}7.0 \pm 0.2 \\
\{6.8 \pm 0.1\}\end{array}$ & $\begin{array}{l}5.53 \pm 0.03 \\
\{5.11 \pm 0.01\}\end{array}$ & \\
\hline $\begin{array}{l}{\left[{ }^{32} \mathrm{P}\right]-\alpha \mathrm{dA} / \mathrm{T}} \\
{[\mathrm{APE} 1]=20 \mu \mathrm{M}} \\
\{[\mathrm{APE} 1]=1 \mu \mathrm{M} \\
{[\alpha \mathrm{dA} / \mathrm{T}]=0.75 \mu \mathrm{M}} \\
=1 \mu \mathrm{M} \\
=1.25 \mu \mathrm{M}\} \\
\\
\text { PAGE analysis }\end{array}$ & & & & & & & $\begin{array}{l}1.57 \pm 0.04 \\
\{1.29 \pm 0.05 \\
0.70 \pm 0.03 \\
0.51 \pm 0.02\}\end{array}$ \\
\hline L-ligand & $4.4 \times 10^{-3 a}$ & $12^{a}$ & & & & & \\
\hline DHU-substrate & $2.9 \times 10^{-2 a}$ & $18^{a}$ & & & & & $51 \times 10^{4 b}$ \\
\hline AP-substrate & $1.8^{a}$ & $120^{a}$ & & & & & $97 \times 10^{4 a}$ \\
\hline
\end{tabular}

Thus, our results revealed that local perturbation around the adA lesion in the DNA duplex allows APE1 to avoid the conformational changes observed earlier in the case of the enzyme binding to an undamaged ligand L containing a nonspecific $\beta$-anomeric nucleoside and specific substrates containing $\mathrm{AP}, \mathrm{F}$, or DHU sites.

\subsection{Anisotropy and fluorescence changes of TAMRA-labeled adA-containing substrates due to APE1 action}

Because we could not register APE1 interactions with the $\alpha \mathrm{dA}$ containing substrate by detecting the intrinsic tryptophan fluorescence intensity, we decided to carry out the stoppedflow experiments at increasing APE1 concentrations using fluorescently labelled DNA molecules. To monitor the formation of the enzyme-substrate complex, we attached TAMRA to the DNA duplex and registered changes in TAMRA fluorescence intensity and anisotropy during the enzymatic process. TAMRA was covalently attached via an amino linker to position 5 of a thymine that was located in the $\alpha \mathrm{dA}$-containing DNA strand and displaced either three $\left(\alpha \mathrm{dA}\left(4 \mathrm{~T}^{\mathrm{TAMRA}}\right) / \mathrm{T}\right)$ or four $\left(\alpha \mathrm{dA}\left(5 \mathrm{~T}^{\mathrm{TAMRA}}\right) / \mathrm{T}\right)$ nucleotides in the $3^{\prime}$ direction from $\alpha \mathrm{dA}$ (Fig. 1). The fluorophore at these positions was probably located next to the protein molecule when the latter was bound to the $\alpha \mathrm{dA}$ lesion.

When APE1 and the TAMRA-containing substrate approached each other, the fluorophore mobility became restricted, thus resulting in an increase in the fluorescence anisotropy signal. Indeed, when TAMRA fluorescence anisotropy was monitored by the stopped-flow method, an increase in the signal (with a subsequent plateau) was observed in the time range from 0 to $\sim 20 \mathrm{~ms}$ (Fig. 5). This increase in the fluorescence anisotropy signal likely reflected the formation of an initial enzymesubstrate complex (ES1). Such initial binding most likely fits a single binding equilibrium. Fitting of the experimental data yielded the forward rate constant for the initial binding of APE1 to the $\alpha \mathrm{dA} / \mathrm{T}$-containing substrate ( $k_{\mathrm{on}}^{\mathrm{bind}}$, Table 1 ). At the same time, we could not determine the precise value of the reverse rate constant $\left(k_{\mathrm{off}}^{\mathrm{bind}}\right)$ presumably because of a strong shift of the equilibrium toward the enzyme-substrate complex. We successfully determined only the upper limit of the reverse rate constant $k_{\text {off }}^{\text {bind }} \leq 1 \mathrm{~s}^{-1}$.

Kinetic traces of TAMRA fluorescence showed an increase in fluorescence intensity within the time range from 0 to $\sim 60 \mathrm{~ms}$ with a plateau after $60 \mathrm{~ms}$ (Fig. 6A and B). This increase likely reflected both formation of an initial enzyme-substrate complex (ES1) and isomerization of the initial complex to yield the second DNA-protein complex (ES2) because formation of the initial complex alone was shown above to take place within 20 ms. Such two-stage binding in all likelihood can be described by two reversible steps, but TAMRA fluorescence kinetic traces (Fig. 6A and B) did not allow us to divide these two steps. Therefore, when processing fluorescence kinetic traces (Fig. 6A and B), we assumed the kinetic constants of the initial enzyme-substrate complex formation $\left(k_{\text {on }}^{\text {bind }}, k_{\text {off }}^{\text {bind }}\right)$ to be equal to the corresponding rate constants obtained during fitting of the fluorescence anisotropy kinetic traces (Fig. 5). Fitting the fluorescence traces yielded the rate constants of initial enzyme-substrate complex isomerization $\left(k_{\mathrm{on}}^{\mathrm{ES} 1}\right.$ isom, $k_{\text {off }}^{\mathrm{ES} 1 \text { isom }}$, Table 1). 
A

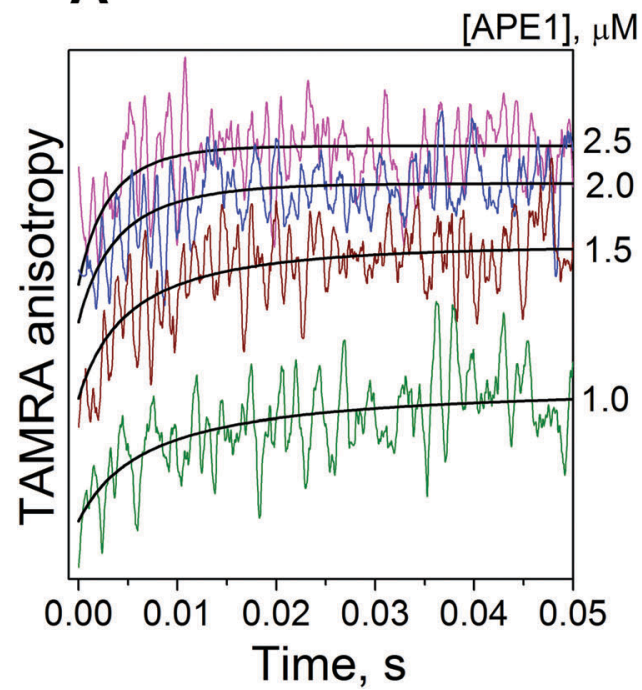

B

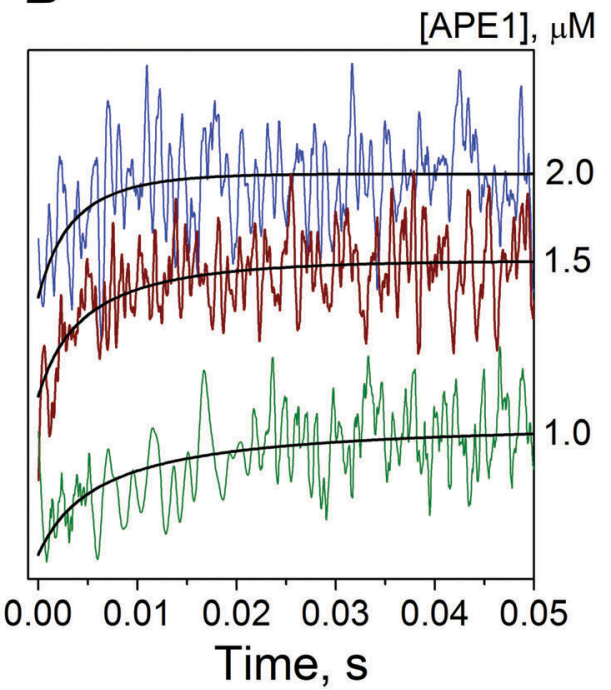

Fig. 5 Anisotropy changes of TAMRA-labeled $\alpha \mathrm{dA}$-containing substrates due to APE1 action. TAMRA anisotropy traces of substrates [ $\left.\alpha \mathrm{dA}\left(4 \mathrm{~T}^{\mathrm{TAMRA}}\right) / \mathrm{T}\right]$ (A) or $\left[\alpha \mathrm{dA}\left(5 \mathrm{~T}^{\mathrm{TAMRA}}\right) / \mathrm{T}\right]$ (B) during their interaction with APE1. The smooth curves are the result of a fitting procedure. The concentrations of the substrates are $1 \mu \mathrm{M}$. The concentrations of APE1 are indicated next to the right axis.
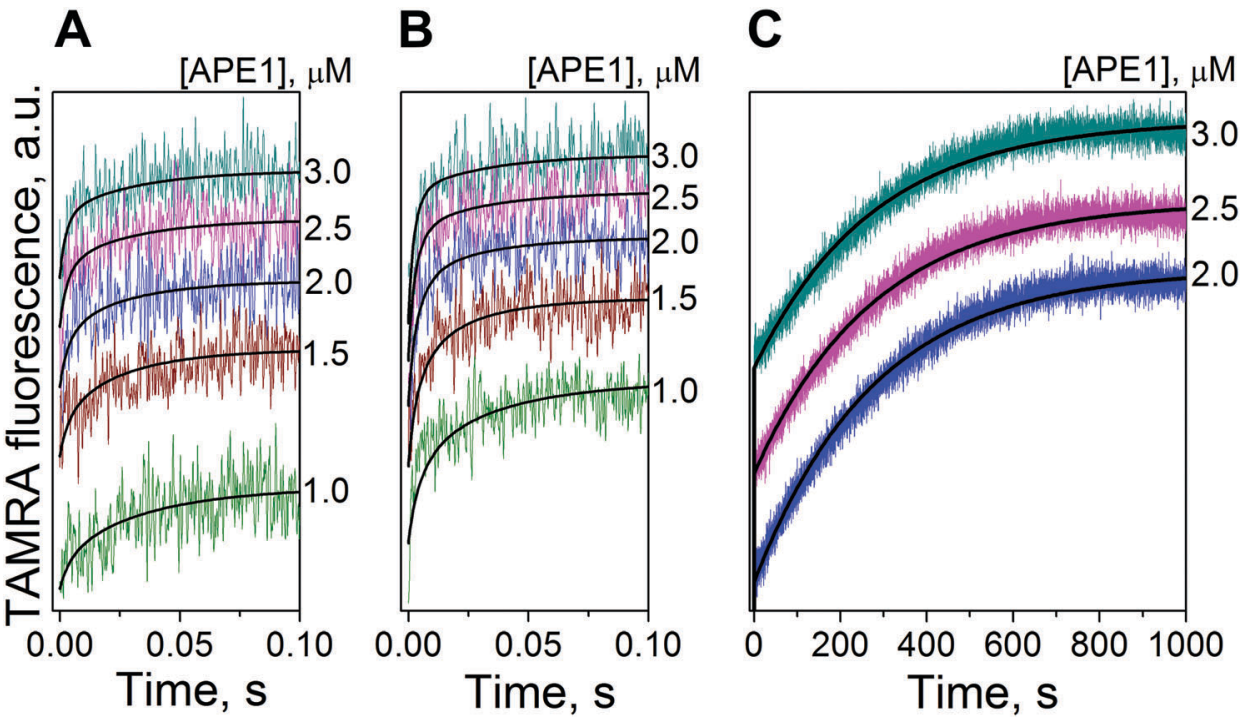

Fig. 6 Fluorescence changes of TAMRA-labeled $\alpha \mathrm{dA}$-containing substrates due to APE1 action. TAMRA fluorescence traces of substrates $\left[\alpha \mathrm{dA}\left(4 \mathrm{~T}^{\mathrm{TAMRA}}\right) / \mathrm{T}\right](\mathrm{A})$ or $\left[\alpha \mathrm{dA}\left(5 \mathrm{~T}^{\mathrm{TAMRA}}\right) / \mathrm{T}\right](\mathrm{B}$ and $\mathrm{C})$ during their interaction with APE1. The smooth curves are the result of a fitting procedure. The concentrations of the substrates are $1 \mu \mathrm{M}$. The concentrations of APE1 are indicated next to the right axis.

The slow increase in the TAMRA fluorescence intensity up to $\sim 900 \mathrm{~s}$ with a plateau was observed in the fluorescence kinetic traces during APE1 interaction with an $\alpha \mathrm{A}\left(5 \mathrm{~T}^{\mathrm{TAMRA}}\right) / \mathrm{T}$-containing substrate (Fig. 6C). This increase probably corresponded to the second slow change in the conformation of the $\alpha \mathrm{dA}$-containing substrate in complex with the protein because APE1 cleaved no more than $10 \%$ of the $5^{\prime}-\left[{ }^{32} \mathrm{P}\right]$-labeled $\alpha \mathrm{dA}$-containing substrate during $900 \mathrm{~s}$ under both single-turnover (see Fig. 4B) and multiple-turnover conditions (see Fig. 4A). Probably, this second conformational change of the $\alpha \mathrm{dA}$-containing substrate was also reversible. We were able to observe only equilibrium accumulation of the third protein complex with DNA (ES3; because this process proceeded very slowly), and we could reliably determine only the rate of accumulation of complex ES3 ( $k_{\text {on }}^{\mathrm{ES} 2}$ isom , Table 1$)$.

\subsection{Fluorescence changes of the 2-aminopurine-labeled adA-containing substrate due to APE1 action}

The dynamics of conformational rearrangements in the $\alpha \mathrm{dA}$ containing DNA substrate during the interaction with APE1 were also recorded by detecting changes in the fluorescence intensity 
A

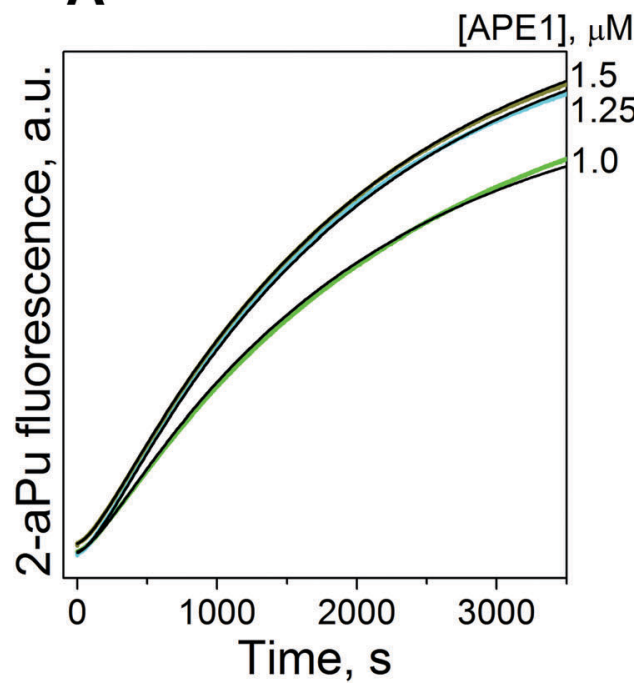

B

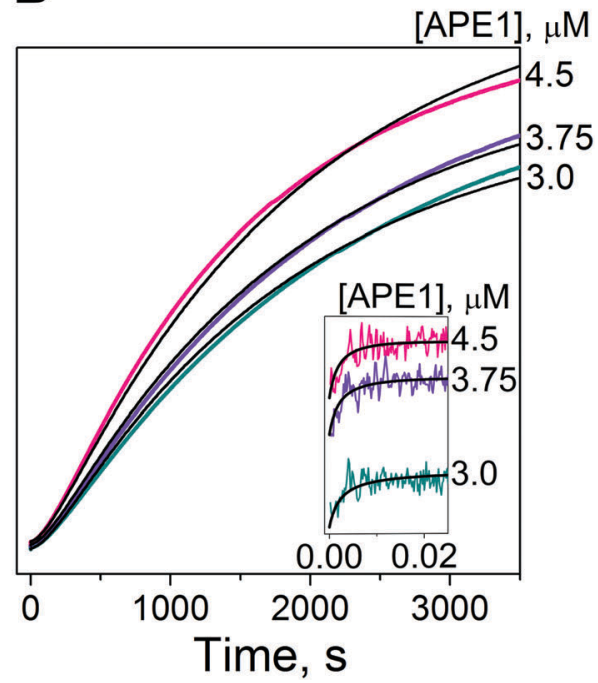

Fig. 7 2-Aminopurine fluorescence traces of substrate (2-aPu) $\alpha \mathrm{dA} / \mathrm{T}$ during its interaction with APE1. Traces were recorded by means of an SX.20 stopped-flow spectrometer. The smooth curves are the result of a fitting procedure. The concentrations of the substrates are $1 \mu M(A)$ or $3 \mu M(B)$. The concentrations of APE1 are indicated next to the right axis.

of the 2-aminopurine residue (2-aPu, a highly fluorescent analog of adenine) incorporated into the DNA strand at the $5^{\prime}$-side of the damaged site. Within a DNA strand, the fluorescence of 2-aPu is quenched due to aromatic stacking with neighboring DNA bases. ${ }^{29}$ The stacking of 2-aPu with aromatic residues of proteins also leads to the quenching of its fluorescence. ${ }^{30}$ Disruption of 2-aPu aromatic stacking increases fluorescence intensity. ${ }^{31}$ Owing to conformational changes of DNA in complex with APE1, one can expect the changes of the fluorescence intensity of 2-aPu residues located in the enzyme-binding site.

During the interaction of $1 \mu \mathrm{M}$ substrate $(2-\mathrm{aPu}) \alpha \mathrm{dA} / \mathrm{T}$ with APE1 $(1.0,1.25$, or $1.5 \mu \mathrm{M})$, the traces of 2 -aPu fluorescence showed a two-phase character (Fig. 7A). In the first phase, the 2-aPu fluorescence intensity showed an increase for periods $<1000 \mathrm{~s}$. This increase coincided with the slow increase in TAMRA fluorescence intensity in the kinetic traces presented in Fig. 6C. A further increase in 2-aPu fluorescence intensity for periods of $>1000 \mathrm{~s}$ corresponded to the second phase (Fig. 7A). The increase in concentrations of the substrate $(2-\mathrm{aPu}) \alpha \mathrm{dA} / \mathrm{T}$ $(3 \mu \mathrm{M})$ and APE1 $(3.0,3.75$, or $4.5 \mu \mathrm{M})$ allowed us to detect changes in 2-aPu fluorescence intensity at the start; this period reflected the step of initial enzyme-substrate complex formation (Fig. 7B). Fitting of the experimental data (Fig. 7B) yielded the forward rate constant value of the initial binding of APE1 with the $\alpha \mathrm{dA} / \mathrm{T}$-substrate (Table 1 ). The reverse rate constant $k_{\text {off }}^{\text {bind }}$ was estimated to be $\leq 1 \mathrm{~s}^{-1}$ as in the case of traces of TAMRA fluorescence anisotropy. The rapid increase in 2-aPu fluorescence intensity at the initial times was followed by a slow two-phase increase in the fluorescence signal. These two slow phases were analogous to the slow phases of 2-aPu fluorescence intensity increase in the kinetic traces obtained at lower concentrations of the reactants (Fig. 7A). Slow phases in the time courses for both series (Fig. 7A and B) probably reflected two slow conformational changes of the enzyme-substrate complex. Most likely, both steps

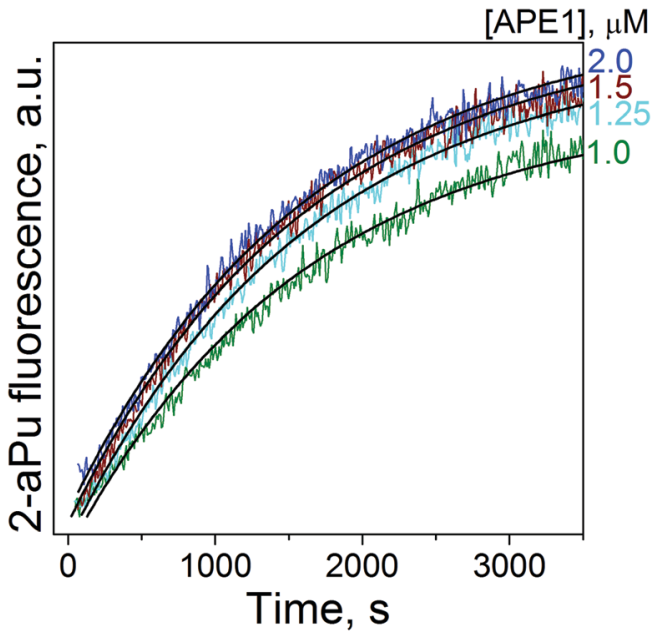

Fig. 8 2-Aminopurine fluorescence traces of substrate (2-aPu) $\alpha \mathrm{dA} / \mathrm{T}$ $(1 \mu M)$ during its interaction with APE1. The traces were recorded using a Cary Eclipse spectrofluorometer. The smooth curves are the result of a fitting procedure. The concentrations of APE1 are indicated next to the right axis.

of the slow conformational changes were reversible, but fitting of the fluorescence traces (Fig. 7) yielded only the rate constant values of the equilibrium accumulation of complexes ES3 $\left(k_{\mathrm{on}}^{\mathrm{ES} 2 \text { isom }}\right.$, Table 1$)$ and ES4 $\left(k_{\mathrm{on}}^{\mathrm{ES} 3 \text { isom }}\right.$, Table 1$)$.

We also used a spectrofluorometer equipped with a closed cuvette to obtain the 2-aminopurine fluorescence traces of substrate (2-aPu) $\propto \mathrm{dA} / \mathrm{T}$ during its interaction with APE1 (Fig. 8). Fitting of these fluorescence traces yielded the rate constant of the equilibrium accumulation of complex ES4 $\left(k_{\mathrm{on}}^{\mathrm{ES} 3 \mathrm{isom}}=(6.17 \pm\right.$ $0.05) \times 10^{-4} \mathrm{~s}^{-1}$ ), which is in good agreement with the corresponding rate constant obtained by fitting of the stopped-flow kinetic traces (Table 1). 


\section{Discussion}

Taken together, our results allowed us to propose a minimal kinetic mechanism of the conversion of an $\alpha \mathrm{dA}$ site in the DNA substrate by APE1 (Fig. 9). As follows from the data described above, APE1 rapidly generates the initial enzyme-substrate complex ES1. This complex undergoes one rapid (ES2) and at least two slow conformational transitions with the formation of complexes ES2 and ES3, ES4, respectively. These conformational transitions correspond to the induced fit of the enzyme active site and its rearrangement into the catalytically competent conformation (complex ES4). After that, the catalytic chemical step of hydrolysis of the substrate $5^{\prime}$-phosphodiester bond takes place, resulting in formation of the APE1 complex with a nicked product EP. After that, the process of APE1 release from the enzyme-product complex occurs and is characterized by the dissociation constant $K_{\mathrm{d}}^{\mathrm{P}}$. This terminal dissociation step likely limits the overall process of enzymatic hydrolysis of an $\alpha \mathrm{dA}$ containing substrate. Therefore, the product of cleavage of an adA-substrate inhibits APE1 competitively in the process of conversion of $\alpha \mathrm{dA}$-containing DNA.

In accordance with the concept of induced fit, the enzyme in complex with the substrate undergoes conformational changes leading to a thermodynamically favorable substrate-bound conformation. $^{32,33}$ The analysis of the cocrystal structure of human APE1 bound to abasic DNA showed that the AP site is very tightly packed in the enzyme active site. ${ }^{20}$ Therefore, the enzyme existing in the optimal conformation for interacting with its major substrate, the AP site, does not have to bind the adA lesion in its own active site. The co-crystal structure of human APE1 bound to adA-containing DNA has not been obtained yet, but it is clear that APE1 should undergo the conformational changes in its active site region to incise the DNA sugar-phosphate backbone on the $5^{\prime}$ side of such a structurally noncognate lesion as $\alpha \mathrm{dA}$.

In our previous study, by monitoring changes in the Trp fluorescence intensity, we showed that APE1 undergoes conformational changes in complex with substrates containing DHU, an AP site, or tetrahydrofuran (F). ${ }^{25}$ Moreover, we have shown that the formation of an APE1 complex with undamaged DNA is also followed by conformational changes in the enzyme. Obviously, the latter conformational changes do not lead to the formation of the catalytically competent complex. Thus, moving along the DNA during a search for specific sites, the enzyme changes its own conformation, probably continuously trying to form a catalytically competent complex. APE1 successfully forms such a complex only when interacting with DNA that contains lesions that are substrates for the enzyme.

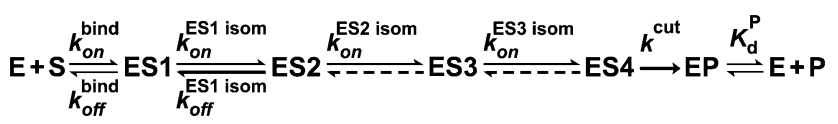

Fig. 9 A minimal kinetic scheme describing conversion of an $\alpha \mathrm{dA}$-containing DNA substrate by APE1. E, APE1; S, DNA substrate; ESi, enzyme-substrate complexes; EP, the complex of APE1 with the DNA product; P, DNA product.
On the other hand, in the present study, we demonstrated that the Trp fluorescence intensity does not change when APE1 interacts with a DNA substrate containing an $\alpha \mathrm{dA} / \mathrm{T}$ base pair. The structural NMR studies established that in solution the $\alpha \mathrm{dA} / \mathrm{T}$ pair resulted in an $18^{\circ} \mathrm{kink}$ of the DNA helical axis and an enlargement of the minor groove around the lesion. ${ }^{15}$

At the same time, structural data have shown that the APE1bound AP-containing DNA bends by $\sim 35^{\circ}$ and its minor groove widens by $\sim 2 \AA$ around the lesion. ${ }^{20}$ The APE1 stabilization of such an abasic DNA conformation is reached due to the interaction of the substrate with amino acid residues emanating from four loops and from one $\alpha$-helix of the protein molecule. Thus, during the initial steps of the binding, APE1 is most likely to bend the DNA and widen its minor groove. Because the DNA substrate containing the $\alpha \mathrm{dA}$ residue is initially distorted as necessary, the conformational changes in the APE1 molecule, previously observed in the cases of the enzyme binding with L-ligand, AP-, F-, and DHU-containing substrates, are absent. It should be pointed out that one cannot rule out the existence of APE1 conformational rearrangements that occur without changes in Trp fluorescence intensity during the enzyme initial binding to the $\alpha \mathrm{dA}$-containing substrate.

We successfully registered formation of an initial APE1 complex, ES1, with the adA-containing DNA substrate by detecting fluorescence anisotropy changes in the TAMRA attached to the DNA. The fluorophore is covalently attached to the thymine residue that is located in the $\alpha \mathrm{dA}$-containing DNA strand and dislodges either three $\left(\alpha \mathrm{A}\left(4 \mathrm{~T}^{\mathrm{TAMRA}}\right)\right)$ or four $\left(\alpha \mathrm{A}\left(5 \mathrm{~T}^{\mathrm{TAMRA}}\right)\right)$ nucleotides in the $3^{\prime}$ direction from $\alpha \mathrm{dA}$. The TAMRA residue at these positions is probably located next to the protein binding site.

The forward rate constant of the initial specific binding of APE1 to the $\alpha$ dA-containing DNA substrate ( $\left.k_{\text {on }}^{\text {bind }}\right)$ is significantly higher than the corresponding constants for the undamaged DNA L-ligand $^{25}$ and the DHU-containing substrate ${ }^{25}$ (Table 1). On the other hand, for the binding of APE1 with the adAsubstrate in the buffer optimal for the NIR pathway, the value of $k_{\text {on }}^{\text {bind }}$ almost coincides with the corresponding value for binding of APE1 to the AP-substrate in the buffer optimal for the BER pathway ${ }^{25}$ (Table 1). The value of the reverse rate constant for the initial specific binding of APE1 to the adA-containing DNA substrate is estimated to be $\leq 1 \mathrm{~s}^{-1}$. This rate constant is lower than the corresponding reverse rate constants measured earlier for the L-ligand, and DHU- or AP-containing DNA substrates ${ }^{25}$ (Table 1).

Thus, these results indicate that in the case of APE1 interaction with $\alpha \mathrm{dA}$-containing DNA, the equilibrium of the initial binding step is shifted toward formation of the enzyme-substrate complex much more strongly than in the cases of the L-ligand or DHU- and AP-substrates. We believe that such an equilibrium shift of the initial binding step may ensure efficient recognition of the $\alpha \mathrm{dA}$ lesion by APE1.

In this work, we have shown that the initial complex of the enzyme with the $\alpha \mathrm{dA}$-substrate (ES1) undergoes a rapid conformational rearrangement (into ES2) followed by at least two slow conformational transitions (into ES3 and ES4). Equilibria of these slow conformational changes are most likely shifted backward strongly; this situation probably explains the relatively 
high value of the equilibrium constant for dissociation of the APE1 complex with the $\alpha \mathrm{dA}$-containing substrate $\left(K_{\mathrm{d}}^{\mathrm{S}}=3.3 \pm 0.2 \mu \mathrm{M}\right)$.

Therefore, our data suggest that during the APE1 interaction with the adA-containing DNA substrate, formation of the catalytically competent complex occurs through mutual conformational changes (induced fit) in the enzyme-substrate complex. One can see that the process of induced fit is extremely slow, much slower than in the case of APE1 interaction with abasic DNA. $^{25}$ In addition, during processing of the DHU-containing substrate, the conformational transitions leading to the formation of the catalytically competent complex take place significantly faster than during the processing of the adA-substrate by APE1. ${ }^{28}$ It has been proposed ${ }^{15}$ that the kink and enlargement of the minor groove of an $\alpha \mathrm{dA}$-containing substrate facilitate the enzymatic access both by reducing the energetic costs of distortion of the initial DNA helix and by further driving of the nucleic acid into its final conformation. Our data proves that the $\alpha$-anomeric structure of the substrate does enhance recognition by the enzyme but dramatically impedes formation of the catalytically competent complex.

The formation of the catalytically competent enzyme complex with the $\alpha \mathrm{dA}$-containing substrate is followed by hydrolysis of the $5^{\prime}$-phosphodiester bond of the substrate. The maximal rate of accumulation of the incised product was observed under singleturnover conditions. The rate constant of the chemical step is very low $\left((1.57 \pm 0.04) \times 10^{-4} \mathrm{~s}^{-1}\right.$, Table 1$)$. This rate is $\sim 5$ orders of magnitude lower than the rate constants of the APE1 hydrolytic cleavage of substrates containing a DHU or AP site $\mathrm{D}^{25,28}$ (Table 1). Nevertheless, the rate-limiting step of the overall enzymatic process is likely the APE1 release from the complex with an $\alpha \mathrm{dA}$-containing product. This conclusion follows from determination of the rates of $\alpha \mathrm{dA}$-product accumulation under multiple-turnover conditions. The observed kinetic constants of $\alpha \mathrm{dA}$-product accumulation are $(1.29 \pm 0.05) \times 10^{-4} \mathrm{~s}^{-1}$, $(0.70 \pm 0.03) \times 10^{-4} \mathrm{~s}^{-1}$ and $(0.51 \pm 0.02) \times 10^{-4} \mathrm{~s}^{-1}$ for adA-substrate concentrations $0.75,1.0$, and $1.25 \mu \mathrm{M}$, respectively, i.e., they depend inversely on the substrate concentrations (Table 1). In our previous study, we also demonstrated that the APE1 complex with the product of cleavage of a DHU-containing substrate is stable, and that the enzyme release from this complex limits the overall enzymatic process. ${ }^{28}$ The value of the rate constant for the limiting step of enzyme release from the complex with the DHU-containing product calculated from the time course of $\left[{ }^{32} \mathrm{P}\right]$-labeled product accumulation is $(1.3 \pm 0.3) \times 10^{-5} \mathrm{~s}^{-1} \cdot{ }^{28}$ Apparently, the existence of a tight complex of APE1 with products of substrate cleavage ensures coordinated binding of substrates to other proteins involved in a repair process and the transfer of substrates from one enzyme to another. Such coordination may protect cells from cytotoxic and mutagenic effects of intermediate repair products such as DNA singlestrand breaks. Meanwhile, our data show that enzyme dissociation from the complex with the $\alpha \mathrm{dA}$-containing product takes place at least fourfold faster than from the complex with the DHU-containing product. Thus, an $\alpha$-anomeric structure at the $5^{\prime}$ terminus at the site of the DNA nick likely accelerates dissociation of the enzyme-product complex.
The comparison of the obtained values of equilibrium dissociation constants revealed that APE1 binds to the $\alpha \mathrm{dA}$ containing product 1.5 -fold more strongly than the $\alpha \mathrm{dA}$ containing substrate. Thus, the $\alpha \mathrm{dA}$-containing product may inhibit APE1 competitively in the process of hydrolysis of the adA-containing substrate. Earlier, ${ }^{28}$ we demonstrated that the product of cleavage of a substrate containing 5,6-dihydrouridine (DHU) can also inhibit this enzyme competitively. The values of equilibrium dissociation constants obtained for interactions of APE1 with a DHU-containing substrate $\left(K_{\mathrm{d}}^{\mathrm{S}(\mathrm{DHU})}=1.3 \mu \mathrm{M}\right)$ and DHU-containing product $\left(K_{\mathrm{d}}^{\mathrm{P}(\mathrm{DHU})}=1.4 \mu \mathrm{M}\right)$ were almost identical, indicating that APE1 showed similar affinity for the DHUcontaining substrate and for the product. According to our data, the lower stability of the complex of APE1 with the $\alpha \mathrm{dA} /$ T-containing substrate-in comparison to the enzyme complex with the $\alpha \mathrm{dA}$-containing product-may be explained by greater perturbation of the structure of the $\alpha \mathrm{dA}$-containing substrate as compared to the structure of the $\alpha \mathrm{dA}$-containing nicked product. Our results revealed that APE1 binds products of the cleavage of DNA containing $\alpha \mathrm{dA}\left(K_{\mathrm{d}}^{\mathrm{P}}=2.3 \mu \mathrm{M}\right)$ or tetrahydrofuran $\left(K_{\mathrm{d}}^{\mathrm{P}(\mathrm{F})}=\right.$ $\left.2.1 \mu \mathrm{M}^{25}\right)$, an abasic-site analog, with almost the same affinity in an identical buffer. At the same time, the binding affinity of APE1 for the $\alpha \mathrm{dA}$-containing product is a little weaker than for the DHU-containing product $\left(K_{\mathrm{d}}^{\mathrm{P}(\mathrm{DHU})}=1.4 \mu \mathrm{M}^{25}\right)$.

The $\alpha \mathrm{dA}$ lesion is not repaired by DNA-glycosylases/AP-lyases but rather by endonucleases during the nucleotide incision repair (NIR) pathway. This repair pathway is conserved from E. coli to yeast and humans. Our in vitro experiments revealed that the human AP endonuclease APE1 can effectively recognize the adA-containing substrate. APE1 incises this substrate significantly more slowly than substrates containing DHU or an AP site, but is released faster from the complex with the $\alpha \mathrm{dA}$ containing reaction product than from a complex with a reaction product containing DHU. All these data indicate that the repair of $\alpha \mathrm{dA}$ via the NIR pathway should have biological significance.

\section{Acknowledgements}

This work was supported by a grant from the Russian Academy of Sciences "Molecular and cellular biology" (6.11) to NAT, OSF. Data analysis was specifically funded by a grant from the Russian Science Foundation (14-14-00063) to OSF.

\section{References}

1 N. Mariaggi, R. Teoule, J. Cadet, H. Dickie and E. Hugues, Radiat. Res., 1979, 79, 431-438.

2 A. Bonicel, N. Mariaggi, E. Hughes and R. Teoule, Radiat. Res., 1980, 83, 19-26.

3 J. A. Raleigh, A. F. Fuciarelli and C. R. Kulatunga, Anticarcinogenesis and Radiation Protection, Plenum Press, New York, 1987, pp. 33-39.

4 K. B. Lesiak and K. T. Wheeler, Radiat. Res., 1990, 121, 328-337.

5 H. Joenje, Mutat. Res., 1989, 219, 193-208.

6 T. Lindahl, Nature, 1993, 362, 709-715. 
7 A. L. Harris, Nat. Rev. Cancer, 2002, 2, 38-47.

8 H. Ide, K. Tedzuka, H. Shimzu, Y. Kimura, A. A. Purmal, S. S. Wallace and Y. W. Kow, Biochemistry, 1994, 33, 7842-7847.

9 L. Gros, A. A. Ishchenko, H. Ide, R. H. Elder and M. K. Saparbaev, Nucleic Acids Res., 2004, 32, 73-81.

10 A. A. Ishchenko, H. Ide, D. Ramotar, G. Nevinsky and M. Saparbaev, Biochemistry, 2004, 43, 15210-15216.

11 H. Ide, T. Yamaoka and Y. Kimura, Biochemistry, 1994, 33, 7127-7133.

12 H. Shimizu, R. Yagi, Y. Kimura, K. Makino, H. Terato, Y. Ohyama and H. Ide, Nucleic Acids Res., 1997, 25, 597-603.

13 H. Ide, H. Shimizu, Y. Kimura, S. Sakamoto, K. Makino, M. Glackin, S. S. Wallace, H. Nakamuta, M. Sasaki and N. Sugimoto, Biochemistry, 1995, 34, 6947-6955.

14 L. Bielecki and R. W. Adamiak, Acta Biochim. Pol., 2001, 48, 103-111.

15 J. M. Aramini, S. H. Cleaver, R. T. Pon, R. P. Cunningham and M. W. Germann, J. Mol. Biol., 2004, 338, 77-91.

16 C. N. Johnson, A. M. Spring, S. Desai, R. P. Cunningham and M. W. Germann, J. Mol. Biol., 2012, 416, 425-437.

17 A. Mazouzi, A. Vigouroux, B. Aikeshev, P. J. Brooks, M. K. Saparbaev, S. Morera and A. A. Ishchenko, Proc. Natl. Acad. Sci. U. S. A., 2013, 110, E3071-E3080.

18 D. J. Hosfield, Y. Guan, B. J. Haas, R. P. Cunningham and J. A. Tainer, Cell, 1999, 98, 397-408.

19 C. D. Mol, D. J. Hosfield and J. A. Tainer, Mutat. Res., 2000, 460, 211-229.

20 C. D. Mol, T. Izumi, S. Mitra and J. A. Tainer, Nature, 2000, 403, 451-456.
21 L. Y. Kanazhevskaya, V. V. Koval, D. O. Zharkov, P. R. Strauss and O. S. Fedorova, Biochemistry, 2010, 49, 6451-6461.

22 G. D. Fasman, Handbook of Biochemistry and Molecular Biology - Nucleic Acids, GRC Press, Cleveland, 1975, vol. 1.

23 J. Sambrook and D. W. Russell, Molecular Cloning: A Laboratory Manual, Cold Spring Harbor Laboratory Press, Cold Spring Harbor NY, 3rd edn, 2001.

24 P. Kuzmic, Anal. Biochem., 1996, 237, 260-273.

25 N. A. Timofeyeva, V. V. Koval, D. G. Knorre, D. O. Zharkov, M. K. Saparbaev, A. A. Ishchenko and O. S. Fedorova, J. Biomol. Struct. Dyn., 2009, 26, 637-652.

26 M. V. Lukina, A. V. Popov, V. V. Koval, Y. N. Vorobjev, O. S. Fedorova and D. O. Zharkov, J. Biol. Chem., 2013, 288, 28936-28947.

27 N. A. Timofeyeva, V. V. Koval, A. A. Ishchenko, M. K. Saparbaev and O. S. Fedorova, PLoS One, 2011, 6, e24063.

28 N. A. Timofeyeva, V. V. Koval, A. A. Ishchenko, M. K. Saparbaev and O. S. Fedorova, Biochemistry (Moscow), 2011, 76, 273-281.

29 E. L. Rachofsky, R. Osman and J. B. Ross, Biochemistry, 2001, 40, 946-956.

30 C. A. Dunlap and M. D. Tsai, Biochemistry, 2002, 41, 11226-11235.

31 T. M. Nordlund, S. Andersson, L. Nilsson, R. Rigler, A. Gräslund and L. W. McLaughlin, Biochemistry, 1989, 28, 9095-9103.

32 D. E. Koshland Jr., Adv. Enzymol. Relat. Subj. Biochem., 1960, 22, 45-97.

33 G. G. Hammes, Y.-C. Chang and T. G. Oas, Proc. Natl. Acad. Sci. U. S. A., 2009, 106, 13737-13741. 